\title{
Discussion on the Construction of Campus Culture in the Environment of New Media based on Computer Network
}

\author{
Kai Ning \\ Harbin Vocational College of Science and Technology, Harbin, Heilongjiang, 150300 China
}

\begin{abstract}
In the computer network and new media environment, continuously strengthening the construction of campus culture in our country has a very important role and significance. It can not only promote the healthy development of students' thoughts and behaviors, but also enable them to complete the learning of relevant subjects and professional knowledge in a more convenient and efficient learning environment. This article first understands the current situation, connotation and significance of campus culture construction in our country under the computer network new media environment, and then further analyzes the main problems faced by our country's campus culture construction under the computer network new media environment, and finally discusses further in this environment. The main methods and strategies to strengthen the construction of campus culture in our country.
\end{abstract}

Keywords: Computer Network; New Media Environment; Campus Culture Construction.

\section{Introduction}

With the advancement of modern science and technology, computer networks and new media have become indispensable communication and information dissemination tools in people's work, study and life, and these technologies play an increasingly important role. It can not only make the communication and exchange between people more smooth and efficient, but also make the connection between people more close. Especially with the high popularity of computer networks and new media, the fields involved and the impact on the future development of human society are very far-reaching. It not only completely replaced the traditional media based on broadcasting, telephone and other media in the way of information dissemination and communication, but also revolutionized the exchange of various information traditions and content. Under such an era background and social environment, the communication and communication methods between people have to be changed accordingly, and for this, can they fully adapt to their requirements. At the same time, under such a background, the construction of campus culture in our country is also facing this unprecedented opportunity and challenge. Therefore, as a builder and leader of campus culture, only by fully recognizing the pros and cons of computer networks and new media technologies, and effectively combining the characteristics of the entire campus environment to construct campus culture can the entire campus culture construction move toward a healthier one, Harmonious direction development [1-2]. Make full use of new media such as online platforms to create a cultural and educational brand project for college students, and effectively realize the reform and innovation of ideological and political work in colleges and universities. In the following, the author combines my own work experience and thinking to discuss with you the relevant content of campus culture construction under the computer-based new media environment, hoping to provide valuable references for the majority of campus culture construction workers.

\section{The Current Situation of Campus Culture Construction in Our Country under the New Media Environment of Computer Network}

With the rapid development of science and technology, the construction of campus culture in our country is playing an unprecedented role. It not only makes the soul of the entire campus, but also plays an important role in promoting the growth of students' thinking. At the same time, a good campus culture can also cultivate the hardworking spirit of its students to think actively and explore continuously. However, with the advent of the age of computer networks and new media, the 
construction of campus culture in our country can no longer fully meet the development needs of the entire social situation. If we continue to develop in accordance with the traditional ideas of campus culture construction, it will inevitably cause huge obstacles and culture. conflict. In the face of this situation, many schools have begun to use computer network technology to build their own new media campus cultural exchange platform based on the characteristics of their own campus environment. Compared with traditional cultural exchange platforms, these new media campus cultural exchange platforms not only fully reflect the characteristics of networking and interactivity, but also effectively realize the mutual integration between digital teaching and campus entertainment life. These changes have had a profound impact on students' daily life and study. It can even be considered from a certain angle that the current campus new media platform has become the main way for students to exchange ideas and culture. For example, through the use of existing platforms, students can not only obtain relevant announcements on campus web pages in time, but also effectively link to relevant information on Weibo and WeChat public platforms. Therefore, as computer networks and new media technologies are highly developed today, these technologies have become the main tools for campus cultural traditions and the exchange of ideas. This change is undoubtedly a good opportunity of the times for the construction of the entire campus culture. At the same time, due to the diversity and efficiency of the Internet and multimedia information exchange, diversified development situations and various risk factors will naturally appear [3].

\section{The Important Connotation and Significance of Campus Culture Construction under the New Media Environment of Computer Network}

In the new media environment of computer networks, our campus culture not only has a diversified development trend, but also its connotation has gradually become diversified. Because of the huge differences in the geographical and social environment of each school, these schools will naturally show obvious differences in the construction of campus culture. Therefore, each school should conduct a comprehensive evaluation based on its own urban culture, campus development history, school purpose, and talent employment direction, so as to summarize the connotation of campus culture that best suits its own situation. For example, the campus culture of technicians or higher vocational colleges should be a process of creating material and spiritual wealth based on the values recognized by the majority of students and faculty. In addition, these creative processes should fully use the school's environment as the space-time carrier, and all members as the main body of teaching activities or campus social activities. In addition, in this basic knowledge, the entire campus teaching should reflect its own cultural and ideological exchange characteristics and a cultural form that integrates scientific research, technology and production practices as a development model. Therefore, under the environment of the computer network and new media era, the connotation of campus culture of each school should naturally have huge differences, which can truly meet the development requirements of the current era background.

In the computer network multimedia environment, it is of great practical significance to continuously strengthen the construction of campus culture. First of all, by strengthening the construction of campus culture, a close connection can be established between campus activities and social development, so that students can enter society more naturally. Secondly, through the construction of campus culture, students can fully feel the cultural characteristics and heritage of the special social environment on campus, thereby establishing unique personality characteristics and forming a differentiated educational background. In addition, through the extensive integration of computer networks and multimedia technologies, the entire campus file construction can be made more of the characteristics of the times, so as to maintain a high degree of unity between campus culture and social culture [4]. 


\section{The Main Problems Faced by the Construction of Campus Culture on Our Country under the New Media Environment of Computer Network}

(1) The innovativeness of the concept of campus culture construction is still seriously insufficient As mentioned earlier, for our country's campus culture, the core connotation of its construction is to build the spirit of campus culture. Therefore, in the new media environment of computer networks, in order to make the entire campus culture construction more effective, the majority of schools must not only always reduce their innovative campus culture construction concepts, but also reflect the special and systematic nature of campus documents. . However, as far as most schools in our country are concerned, their capabilities in these areas are still very lacking. In particular, the huge impact and far-reaching impact of computer networks and new media on the entire campus culture has not been fundamentally understood and understood. analyze. Therefore, it is often difficult for them to show sufficient innovation in how to quickly promote the network and informationization of our campus culture. In addition, some schools are also very at a loss as to how to systematically arrange and design a technology-assisted campus culture on campus. They neither have the top-level design idea of "computer network + new media + campus culture" platform, nor have they developed an APP platform that can satisfy the ideological and cultural exchanges of faculty and students on campus. This shows that the current innovation of campus culture in our country is still seriously inadequate.

(2) The construction of campus culture has not made full use of scientific and technological carriers such as computer networks and new media

With the rapid development of computer networks and new media technologies, if the majority of schools want to achieve substantial breakthroughs in their own campus culture construction, they must fully integrate the current era background and social environment and make full use of computer networks and new media technologies. Technological Achievements. However, as far as the current major schools in our country are concerned, due to their lack of strong innovative development concepts, they are still very confused about how to use computer networks and new media technologies as carriers to strengthen and expand their own campus cultural construction. At the same time, they are very contemptuous of the rationalized application of these technologies. For example, for the positional construction of campus cultural activities, many colleges and universities have not established a cultural development model that combines online and offline, and at the same time, how to use new media to effectively carry out campus cultural dissemination often appears very formal and formal. It is superficial, without realizing in-depth exploration and thinking based on the real needs of the majority of students and faculty.

(3) The construction model of the entire campus culture needs further exploration and innovation

In the information age with the rapid development of computers and the Internet, new media technology embodies unprecedented communication, openness, and entertainment interaction. Therefore, in order to do a good job in the construction of campus culture under the computer network and new media environment, we must also work hard on the construction mode of the entire campus culture. However, in many schools in our country, the research on the innovative model of campus culture construction is still relatively traditional and backward. For example, many colleges and departments pay little attention to how to cultivate students' ability to use new media technology. Not only did the students not know how to make and edit the short video content that they needed to express and disseminate by using the relevant technologies of the new media, but they also knew nothing about the rules of the entire new media platform. At the same time, many schools even believe that the excessive development of network and new media technologies will inevitably have a huge impact on students' professional learning, so they are neither willing to explore the mode of campus culture construction, nor dare to take it lightly. Make innovations in the methods of campus culture construction.

(4) The dominant position of the entire campus culture is facing unprecedented challenges

After a retrospective analysis of my country's traditional media application experience, we can find that the media carrier that the construction and dissemination of traditional campus culture relies 
on is often relatively single and has the characteristics of directional communication. Although these characteristics make the construction of traditional campus culture have certain limitations, it is undeniable that the campus culture that is not carried by traditional media truly reflects the authority and dominance. It not only enables the majority of students to establish a more serious and orthodox cultural image, but also is very conducive to the spread of mainstream ideas, behaviors and systems. However, with the development of computer networks and new media, the dominant position of traditional campus culture construction is gradually declining, and to a large extent shows new characteristics and new trends such as freedom, interaction and openness. In addition, in such an environment, students even use new media as a carrier to show their own personality and independent ideas. It can be seen that the dominance of the entire campus culture is facing unprecedented impacts and challenges [5].

\section{The Main Methods and Strategies to Further Strengthen the Construction of Campus Culture in Our Country under the New Media Environment of Computer Networks}

(1) Change the inherent concept and fully realize the innovation of the concept of campus culture construction

For any kind of cultural construction, the guiding ideology of its actions is undoubtedly an advanced idea. Therefore, to do a good job in the cultural construction of the entire campus under the new media environment of the computer network, it is of vital importance to achieve breakthroughs and innovations in the ideological and theoretical aspects of the entire campus cultural construction. First of all, the development concept of the entire campus culture construction should reflect the development trend of science and technology and the Internet as much as possible. Especially for some high-value ideas that are widely accepted and recognized by the society or the masses, the campus culture builders should try their best to integrate them into the concept of campus culture construction. Secondly, in the core concept of campus culture construction, in addition to always adhering to the principle of innovation and development, it should also reflect the characteristics of humanization, diversification and comprehensiveness to the greatest extent. In addition, in order to make the whole concept of campus culture construction more contemporary, regional and cultural, as the relevant workers of campus culture construction, they should fully focus on the future layout of campus culture construction, so as to do a good job in the top-level design of concept innovation.

(2) Do a good job in the innovation of campus culture construction using computer networks and new media technologies as carriers

To fully realize the construction and innovation of campus culture, in addition to innovative and forward-looking theories as the guiding ideology, it is also necessary to make full use of cultural communication and communication media such as computer networks and new media technologies. Therefore, in the specific implementation process, colleges and universities should firmly establish the thinking and development awareness of "computer network + new media + campus culture", so as to build a media communication platform and carrier with innovative driving force. Secondly, in order to make the entire campus culture construction more innovative and technological, the campus culture builders should make full use of the campus' own advantages in talents and technology, to fully realize the information and intelligence of the campus culture construction platform. And efficient. In addition, the construction of campus culture should also fully take into account the needs of students for the cultivation and shaping of cultural literacy, so as to create a more ideological and creative comprehensive ideological and cultural exchange platform.

(3) Exploring a new development model of campus culture construction based on the development trend of the times

For the construction of modern campus culture, in addition to having innovative development concepts and making good use of the two elements of carriers such as computer networks and new media, it should also fully explore its own development status and future development trends to 
explore more distinctive features. The new development model of campus culture construction. First of all, the campus culture builders should fully build a comprehensive communication platform that focuses on cultural propaganda, guidance, communication and service in the campus culture construction model, and continuously realize the integration and innovation of the entire campus culture. In addition, in order to correctly guide the cultural public opinion of campus culture construction, campus culture builders should use the comprehensive communication platform built to develop web-based columns, and take the entire campus culture as the focus of all interactive content, so as to continuously improve The recognition of campus culture by the majority of students.

(4) Actively take targeted measures to further strengthen the dominance of the entire campus culture

As mentioned above, with the development of computer networks and new media, the dominant position of the entire campus culture is facing huge challenges. Under such circumstances, the construction of campus documents should not sit still, but should take specific measures to respond to the requirements of the society and the development of the times, so as to further strengthen its own dominance. In addition, as a builder and leader of campus culture, we should also pay special attention to the use of the Internet and big data technology to accurately analyze the ideological trends of the majority of students, so as to recommend more positive campus cultural content to them.

\section{Conclusion}

In summary, with the continuous development of computer networks and new media technologies, people's life, study and work methods are undergoing unprecedented changes. Under such an era background and social environment, the construction of campus culture in our country should naturally change accordingly. This is not only the objective need of the entire era and social development, but also an important manifestation of social progress. Therefore, as a builder and leader of the entire campus culture, we should carry out in-depth exploration of cultural construction based on these technological changes and the characteristics of the current campus environment, so as to make the entire campus cultural construction more contemporary and creative.

\section{Acknowledgments}

Fund Project: Research Result of Key Topics of Heilongjiang Provincal Educational Science Planning in 2022.

\section{References}

[1] Zhang Juan. The construction of campus culture under the new media environment of computer network [J]. Electronic Technology and Software Engineering, 2018, (09): 7.

[2] Song Yang. The construction path of college campus culture under the new media environment [J]. Shenhua (Part 2), 2020, (05): 64.

[3] Zheng Junjun. Innovative research on the campus culture construction of local undergraduate colleges under the new media environment [J]. Journal of Honghe University, 2021, 19(01): 96-99.

[4] Ouyang Xiaoting. New exploration of campus culture construction in higher vocational colleges under the new media environment [J]. Frontier Economy and Culture, 2021, (03): 105-107.

[5] Zhao Xiupi. Opportunities, challenges and countermeasures for the construction of campus culture in colleges and universities under the new media environment $[\mathrm{J}]$. Chinese Journal of Multimedia and Network Teaching (Mid-term), 2019, (02): 120-121. 